\title{
Anatomical Variants of the Circle of Willis and Brain Lesions in Migraineurs
}

\author{
C. Cavestro, L. Richetta, M.R. L'Episcopo, E. Pedemonte, S. Duca, \\ C. Di Pietrantonj
}

\begin{abstract}
Background: Some reports demonstrated vascular alterations in brain magnetic resonance imaging (MRI) in migraineurs and a relationship between circle of Willis (Circle) variants and lacunar brain infarcts. We examined anomalies of the whole circle of Willis and their relationship with vascular brain lesions in migraineurs, to identify any possible vascular mechanism in migraine. Methods: We studied, with a cohort controlled study, the circle of Willis in migraineurs seen consecutively in our Headache Center, and in non-headache controls, using angio-MRI of the brain. Statistical analysis used ANOVA, Scheffè's criterion, t-student test. Results: We recruited 270 migraineurs (204 without aura (MWOA), 66 with aura (MWA) and 159 controls. Migraineurs presented an anatomical variant in $108(40 \%)$ cases with 34 controls (21.4\%) presenting a variant. We found a significant association between MWOA and variants (OR=2.4 CI95\% [1.5 to 3.9]) and between MWA and variants (OR=3.2 CI95\% [1.6 to 4.1]). Unilateral posterior variants with basilar hypoplasia are statistically associated only with MWA compared to controls (OR=9.2, CI95\% [2.3 to 37.2]). Thirty-three percent of MWOA and 24\% of MWA sufferers present some kind of brain lesion, included 2\% of infra-tentorial lesions. We did not find any statistical association between the presence of Circle variants and ischemic lesions on MRI (OR=1.5 CI95\% [0.68; 1.94]), or with infratentorial lacunar lesions ( $\mathrm{OR}=1.58 \mathrm{CI} 95 \%$ [0.48 to 5.24]). Conclusions: Anatomical variants of the Circle of Willis are significantly more frequent in migraineurs; posterior anomalies are more frequent in MWA, suggesting a vascular mechanism provoking changes in cerebral blood flow, thereby stimulating cortical spreading depression.
\end{abstract}

RÉSUMÉ: Les variantes anatomiques de l'hexagone de Willis et du cerveau. Contexte : Certaines publications font état d'altérations vasculaires à l'IRM du cerveau chez les migraineux et d'une relation entre des variantes de l'hexagone de Willis et les infarctus cérébraux lacunaires. Nous avons examiné les anomalies de tout l'hexagone de Willis et leur relation aux lésions vasculaires du cerveau chez des migraineux afin d'identifier un mécanisme vasculaire possible dans la migraine. Méthode : Nous avons effectué une étude de cohorte contrôlée chez des patients migraineux, ayant consulté de façon consécutive à notre clinique de céphalée, et chez des témoins non migraineux pour étudier l'hexagone de Willis par angio IRM cérébrale. Les données ont été analysées par les méthodes statistiques suivantes : l'ANOVA, le critère de Scheffe et le test t de Student. Résultats : Nous avons recruté 270 patients migraineux, soit 204 sans aura (MSA) et 66 avec aura (MAA), et 159 témoins. Cent huit migraineux (40\%) et 34 témoins $(21,4 \%)$ étaient porteurs d'une variante anatomique. Nous avons constaté une association significative entre la MSA et les variantes anatomiques (RR $=2,4$; IC à $95 \% 1,5$ à 3,9) et entre la MAA et les variantes anatomiques (RR = 3,2; IC à 95\% 1,6 à 4,1). Les variantes postérieures unilatérales avec hypoplasie basilaire sont associées statistiquement avec la MAA seulement par rapport aux témoins (RR = 9,2; IC à 95\% 2,3 à 37,2). Trente-trois pour cent des patients atteints de MSA et $24 \%$ de ceux atteints de MAA ont une lésion au cerveau, dont $2 \%$ de lésions sous-tensorielles. Nous n'avons pas constaté d'association statistique entre la présence de variantes de l'hexagone de Willis et la présence de lésions ischémiques à l'IRM (RR = 1,5; IC à $95 \% 0,68$ à 1,94) ou de lésions lacunaires sous-tensorielles ( $R R=1,58 ;$ IC à 95\% 0,48 à 5,24). Conclusions : Les variantes anatomiques de 1'hexagone de Willis sont significativement plus fréquentes chez les patients migraineux. Les anomalies postérieures sont plus fréquentes dans la MAA, ce qui est en faveur d'un mécanisme vasculaire provoquant des changements dans le flux sanguin cérébral, stimulant ainsi une dépression se propageant au cortex.

Can. J. Neurol. Sci. 2011; 38: 494-499

Migraine is a complex neurological phenomenon presenting some characteristics typical of a vascular brain disorder. ${ }^{1}$ Lovrencić-Huzjan studied intracranial circulation with Doppler scanning in 1998 and found a significantly greater prevalence of vertebral artery hypoplasia in migraineurs with aura (MWA) compared to controls ${ }^{2}$. Since 2005, further studies have evaluated the Circle of Willis (Circle) in migraineurs using magnetic resonance imaging (MRI), a more reliable method than Doppler. ${ }^{3,4}$ These studies are not conclusive however, being either retrospective, small, or having examined only some of the Circle's possible variant morphologies. Despite these draw- backs, a complex picture seems to be emerging, with some studies implying that migraineurs may be more at risk from

From the Department of Neurology (CC, MRL, EP), San Lazzaro Hospital, Alba; Department of Neuroradiology (LR), Maggiore Santissima Trinità Hospital, Fossano [CN]; Department of Neuroradiology (SD), Koelliker Hospital, Turin; Regional Epidemiology Service (CDP), [Servizio Regionale Epidemiologia] SeREMI, ASL AL Alessandria, Italy.

Received June 21, 2010. Final Revisions Submitted November 22, 2010. Correspondence to: Cinzia Cavestro, Headache Center, Department of Neurology, San Lazzaro Hospital, A.S.L. CN2, Alba (CN), Italy. E-mail: cicaves@alice.it. 
ischemic brain lesions, ${ }^{5}$ and others, such as the one conducted by van der Grond et al in 2004, that describe fetal configurations of the Circle that appear to protect against lacunar brain infarcts in elderly patients. ${ }^{6}$ Using these data as a basis, we undertook a MRI study of the circle of Willis in both migraineurs and a control group of non-headache patients, with the objective of: 1 . documenting Circle morphologies, and 2. uncovering any links between Circle variants and the presence of gliotic areas or infarcts in the brain in migraineurs.

\section{Patients And Methods}

This is a cohort controlled study undertaken from January 2005 to December 2007. We recruited two groups of subjects: a study group of migraineurs and a control group of people without any headache type. Eligible patients were individuals suffering from migraine seen consecutively at the out-patient headache center of our hospital from January 2005 to December 2007. A diagnosis of migraine was made according to the International Headache Classification currently in use and patients with other headache diagnoses were excluded from the study. ${ }^{1}$ For each patient we recorded age, sex, type of migraine (with or without aura), age of onset, frequency (number of days per month with headache at time of recruitment with mean value calculated over the previous three months) and concomitant disorders. All study patients underwent a general medical and neurological examination, routine blood tests and brain MRI with angiogram sequences (Angio-MRI). The controls were all consecutive individuals undergoing brain MRI in the hospital's department of radiology with headache as the only criterion of exclusion from this group. For each control we recorded age, sex and the illness for which MRI was being performed. Recruitment of controls was done by radiologic technicians and radiologists blindly evaluated Angio-MRIs and MRIs for all patients. Brain lesions were not annotated for controls. Written informed consent was obtained from both groups, as required by Italian law. Magnetic resonance scans were performed using Philips $1 \mathrm{~T}$ release Intera or Achieva apparatus. Sequences used were: T1 SE (TR 360, TE 12, Fov $340 \mathrm{~mm}$, Thickness $6 \mathrm{~mm}$ ), DP T2 SE (TR 2200, TE 20/90, Fov 290, Thickness 6 mm), FLAIR (TR 6000, TE 120 , TI 2000, Fov 270, Thickness $6 \mathrm{~mm}$ ) and DW (TR 4300, TE 104, Fov 250, Thickness 6). The angio sequences were acquired using T13D FFE protocol (TR $25 \mathrm{~ms}$, TE 4,7 ms, Flip Angle 20 , head coil, field of view $220 \mathrm{~mm}$, matrix reconstruction 512 and slice thickness $0.5 \mathrm{~mm}$ ), subsequently reformatted in post processing using MIP (maximum intensity projection) reconstruction (AP, RL, FH, 12 slices, $15^{\circ}$ ) and multiplanar reformatting reconstruction. We divided anatomical variants observed in the Angio-MRI into three main types, as follows:

1. Normal Circle of Willis, comprising both anterior cerebral arteries, anterior communicating artery, both medial cerebral arteries and both posterior cerebral arteries emerging from the basilar artery.

2. Anterior variants: anterior Circle anomalies with hypoplasia or displacement of anterior cerebral artery and/or anterior communicating artery.

3. Posterior variants: posterior Circle anomalies, including partial or complete fetal configuration of posterior cerebral arteries, with or without basilar hypoplasia. In the posterior circle, any abnormality of the basilar artery was noted.
Definition of type of variants considered the articles by Hartkamp et al, ${ }^{7}$ and by van der Grond et $\mathrm{al}^{6}$. Basilar artery hypoplasia definition was adapted from Hartkamp et al, ${ }^{7}$ though after considering a sample of our resident general population, where the mean diameter of basilar arteries was found to be around $3.5 \mathrm{~mm}$ we took, as hypoplastic, basilar arteries with a diameter of less than $1.5 \mathrm{~mm}$ (95\% centile). This value is slightly greater than that suggested by Krabbe and Hartkamp in their article $^{8}$, who found an average diameter of around $3 \mathrm{~mm}$, narrower than ours by $0.8 \mathrm{~mm}$.

Brain lesions were divided into two main groups, as below:

1. Small, deep white matter lesions less than $5 \mathrm{~mm}$ in diameter.

2. Larger lesions [lacunar (lesions with diameter of 5-15 mm $)^{9}$ or major ischemic lesions] greater or equal to $5 \mathrm{~mm}$ in diameter. Confluent lesions were included in this group.

Where dilated Vircow-Rubin spaces were observed, they were not considered as brain lesions. We defined these two types of brain lesion by adapting definitions from van der Grond et $\mathrm{al}^{6}$.

When we originally designed the study in 2004 , we estimated Circle variants as being present in around $50 \%$ of the healthy population, requiring 116 individuals in both groups in order to arrive at a 5\% significance level, with $90 \%$ power and OR (Odds Ratio) $>=2.5$. We used the chi-square test and OR to assess the association between items such as gender, migraine, presence of circle of Willis variants on Angio-MRI, and the presence of gliosis or ischemic lesions on MRI. ANOVA was used to test the association between age and study groups and multiple comparisons were performed using Scheffè's criterion. The TStudent was used to test the association between age at headache onset, headache frequency and study group, with significance taken at the 0.05 level. We performed a post hoc analysis concerning the sub-groups defined by the different sub-variants of the Willis' circle: that is, anterior variants (unilateral, bilateral) and posterior variants (unilateral, unilateral with basilar hypoplasia, bilateral, bilateral with basilar hypoplasia). All statistical analyses were performed using the SAS System statistics package Ver.9.1.

\section{RESULTS}

We recruited 270 patients with migraine and 159 controls. The study group included 204 migraine patients without aura (MWOA) and 66 with aura. Characteristics of the study population are included in Table 1. Migraine patients were significantly younger than controls. There was no difference in mean age of headache onset between MWOA and MWA patients. Patients with MWOA did however have a higher frequency of migraine attacks than those with MWA. Sub- group analysis did not show any difference in mean number of headache episodes among the groups of Circle variants. The migraine group presented a wide variety of co-morbid disorders and during statistical work-up we paid particular attention to those that related directly to vascular brain lesions. In the control group, pathologies for which MRI was being performed included several disorders, either confirmed or suspected, with the only prevalent being cerebrovascular disease (63 cases: 40 ischemic, 10 transient ischemic, 5 bleeding, 5 aneurysm, 1 cavernoma, 1 venous thrombosis, 1 internal carotid stenosis). Other disorders were: cranial nerve disorders (20 cases), 
Table 1: General characteristics of the study population

\begin{tabular}{|c|c|c|c|c|c|c|}
\hline & $\underset{10-204)}{\sin (2 x}$ & $\begin{array}{l}314.2 \\
(n-t) b)\end{array}$ & $\begin{array}{l}\text { Controk } \\
(11=i 59)\end{array}$ & 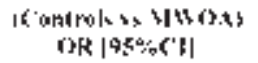 & 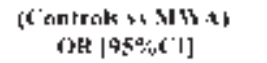 & 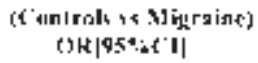 \\
\hline M1: & 95,29196 & 1512250.3 & 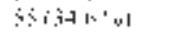 & - & . & - \\
\hline 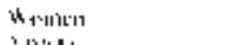 & 151217.407 & $=11-7.0 .1$ & $111+1354 ?$ & 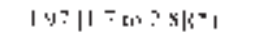 & : & יום ב. ו|קי. \\
\hline וाון & 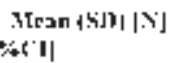 & | & | & |31] & . & \\
\hline 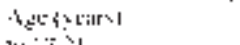 & $113.111+.=1 ; ?]$ & $A s: 1|: x|:\langle 1,1$ & צ & (1) & 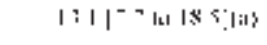 & I.: 3|ו 3 \\
\hline & 214004 & Hitik & timul ruls & \multicolumn{2}{|c|}{ 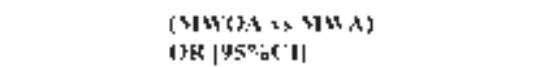 } & \\
\hline 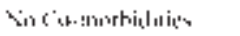 & $12 x i e^{2} s x^{2}$ & ום & . & \multicolumn{2}{|c|}{ 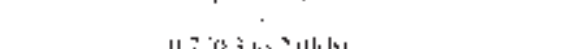 } & \\
\hline 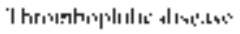 & וט. & 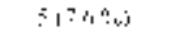 & . & \multicolumn{2}{|c|}{ וי| ימו1 } & \\
\hline 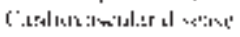 & 3il:? ? & וע" & - & \multicolumn{2}{|c|}{$\therefore$ | } & \\
\hline Sizֵ & $1 ; \operatorname{res} \theta=01$ & 51000 & - & \multicolumn{2}{|c|}{ 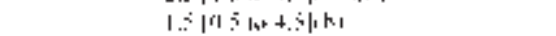 } & \\
\hline simatin: & - & - & 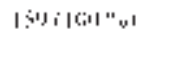 & \multicolumn{2}{|c|}{ 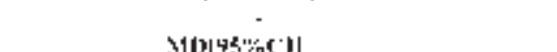 } & \\
\hline 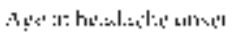 & . & | & - & \multicolumn{2}{|c|}{$1 . \therefore|-|<14++.1 \mid+1 \times 1$} & \\
\hline 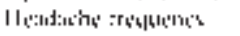 & | & 1 & - & \multicolumn{2}{|c|}{ 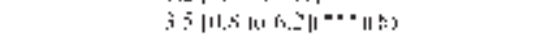 } & \\
\hline
\end{tabular}

MWOA: Migraine Without Aura; MWA: Migraine With Aura; OR: Odds Ratio; MD: Mean Difference; (SD): Standard Deviation; [N]:sample size; [95\%CI]: 95\% Confidence Interval; $\left(^{*}\right)$ OR >1 statistically significant association between sex (female) and presence of migraine ; (a) Sheffè's criterion; (b) (MWOA vs MWA); (**) OR >1 statistically significant association between presence of cardiovascular disorders and presence of migraine MWA; $(* * *)$ MD statistically significant.

epilepsy (24 cases), dementia (1 case), liquoral hypotension (1 case), Horner's Syndrome (1 case), amyotrophic lateral sclerosis (1 case), stupor (1 case), multiple sclerosis (2 cases), infection (2 cases), pseudotumor coerebri (1 case), hereditary ataxia (1 case), inflammatory diseases ( 3 cases), dizziness and vertigo (14 cases), genetic disorders ( 2 cases), trauma (3 cases), loss of consciousness (12 cases), neoplasia (2 cases), and psychiatric disorders (5 cases). Variants of the circle of Willis, their distribution and statistical association with migraine typology are described in Table 2. Data have been sex-adjusted during statistical analysis, without any significant difference for sex being found. In our study, $60 \%$ of migraine subjects presented a normal Circle of Willis (162 individuals) and 40\% an anatomical variant, (108 subjects). Of the control group, $78.6 \%$ (125 subjects) had a normal circle and $21.4 \%$ a variant one (34 subjects): see Table 2. Statistical analysis demonstrated a significant association between Circle variants and both MWOA $(\mathrm{OR}=2.4 \mathrm{CI} 95 \%$ [1.5 to 3.9]) and MWA $(\mathrm{OR}=3.2 \mathrm{CI} 95 \%$ [1.7

Table 2: Variants of the circle of Willis and their distribution and statistical association with migraine typology

\begin{tabular}{|c|c|c|c|c|c|c|}
\hline & $\begin{array}{l}\text { M140. } \\
n-204\end{array}$ & $\begin{array}{l}114,1 \\
n=66\end{array}$ & $\begin{array}{l}\text { Cirintrols } \\
n=159\end{array}$ & 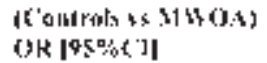 & 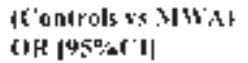 & 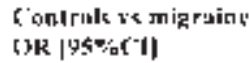 \\
\hline & 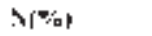 & $N(\%)$ & $\mathrm{N} 1 \% 1$ & & & \\
\hline Virırnul circk af W illis & | & I & $\therefore 5_{1} x^{2} n^{n} 01$ & - & - & \\
\hline Siariants & 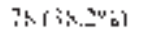 & 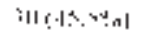 & id & $2+11.4165 .4 \mid$ & 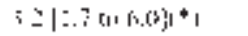 & 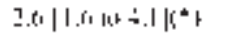 \\
\hline 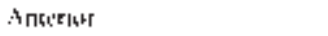 & $201^{3} \times x^{n} \cdot v !$ & n! & 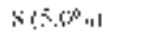 & 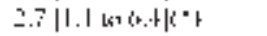 & 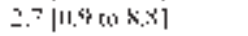 & 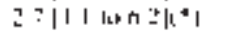 \\
\hline ' & 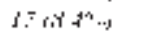 & 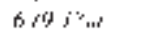 & $x$ x & $=1$ | & . $x$ X & 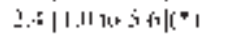 \\
\hline Bjuidistrol & St? & . & & $\therefore 4 \mid$ & - & | \\
\hline 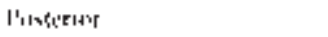 & $A \leqslant 123 . z_{n}^{n}$ & 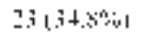 & 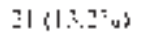 & | & $i 211.405 .10 \% 1$ & $\therefore$ \\
\hline 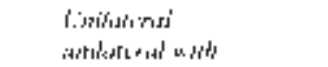 & \& & $i<, \because-r^{\circ}$ & $18^{-50} 5^{2}$ & $\because 9[1.4 \mathrm{~kg} 512 \mathrm{l}$ & 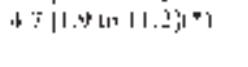 & 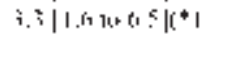 \\
\hline 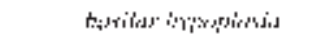 & נ...'ינז דinin & 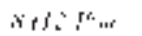 & $i(1)=$ & | & 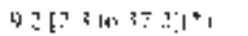 & 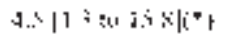 \\
\hline Eskitseris' & נים" & & $i \cos$ & | & 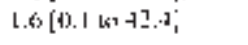 & 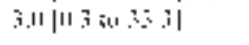 \\
\hline 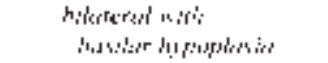 & ! & . & 5 с & 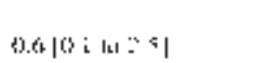 & $\mid 1.6[0.1 \mathrm{loc}(\mathrm{n} .11]$ & 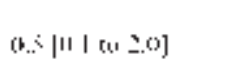 \\
\hline Itockls & $\mid 11\left\langle 4 . x_{0}\right|$ & $\mid$ & $\left.S_{1} i, i^{4}\right)$ & ב.I|י.? & 1). ? [0.1 |L, fr.t] & 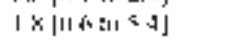 \\
\hline 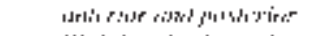 & $x>i v v^{\prime \prime}$ & - & $+8: 5 \cdot .$. & 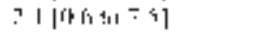 & |נ & $1.8 \mid 11.5[1,5.5]$ \\
\hline H & $\therefore i n$ & ). & $j m g^{\prime} \cdot$ & |? & i.to[o.210 ins] & $2 .+110$ (1) \\
\hline
\end{tabular}

MWOA: Without Aura, MWA: With Aura; OR: Odds Ratio; [95\%CI]: 95\% Confidence Interval; (*) OR >1 statistically significant association between presence of variants and their type, and migraine, sex adjusted. 
to 6.1]) - after control for gender. Sub-group analysis evidenced an association between the presence of posterior Circle anomalies and migraine typology, with the presence of basilar artery hypoplasia statistically associated only with MWA compared to controls (OR=9.2 CI95\% [2.3 to 37.2]) (see Table 2). Circle variants were similarly distributed in both sexes $\left(\mathrm{chi}^{2}\right.$ $=0.831 \mathrm{df}=1 \mathrm{p}=0.362 ; \mathrm{OR}=0.8195 \% \mathrm{CI}[0.52$ to 1.27$])$, within control, MWOA and MWA groups (OR=0.70 95\% CI [0.44 to 1.12]). Brain lesions evidenced by MRI were assessed only for the migraine group (270 cases), with lesion types and migraine group compared in Table 3. In our population, 33\% of MWOA and $24 \%$ of MWA sufferers presented some kind of lesion. These were mainly lacunar lesions in MWOA patients, with both lacunar and gliotic lesions present in MWA subjects (Table 3). The most common site for brain lesions was the sub-cortical supra-tentorial region, with only about $2 \%$ of MRI scans demonstrating infra-tentorial lacunar lesions. Data analysis showed no evidence of association between the presence of lesions and headache type ( $\mathrm{OR}=0.6 \mathrm{CI} 95 \%$ [0.3 to 1.2$]$ ), even after control of gender and co-morbid conditions. There were no associations between the presence of Circle variants and ischemic lesions on MRI (OR=1.5 CI 95\% [0.68; 1.94]), or variants and infra-tentorial lacunar lesions $(\mathrm{OR}=1.58 \mathrm{CI} 95 \%$ [0.48 to 5.24$])$.

\section{Discussion}

\section{Circle of Willis variants}

The migraineurs in our study presented a variant Circle in $40 \%$ of cases. We found a significantly higher percentage of all types of Circle variants in migraineurs when compared to controls: for MWA, a unilateral posterior circle variant together with basilar artery hypoplasia was found to be significantly more frequent than in controls. Our study is the first to consider all Circle variant types in migraineurs with and without aura, compared to non-selected non-headache controls using a large study population. A previous study, conducted on the frequency of vascular malformations in a migraine population, ${ }^{3}$ provided very limited information on the presence of anatomical Circle variants. In addition, the study was retrospective and lacked precise data on migraine and Circle variant typology. Very recently, Bugnicourt has also reported a similar link between incomplete posterior circle of Willis and migraine with or without aura (48\% incomplete circle in migraineurs and $18 \%$ in controls), although in a smaller study population. ${ }^{10}$ Ikeda et al compared a group of migraineurs (MWA 63, MWOA 422) and healthy controls (481) for the presence of fetal Circle variants only, without finding any significant difference between the two groups. 4

To check for chance, we recruited as controls a non-selected population undergoing brain MRI for various diagnoses, the only criterion for inclusion being the absence of headache. Almost $50 \%$ of controls were being scanned for suspected cerebrovascular disorders; sub-analysis subsequently demonstrated that Circle variants have the same prevalence in this group, $21 \%$, as the control group as a whole, with no difference in frequency of variant types. In our study, the non-headache population presented a complete Circle in around $79 \%$ of subjects. In the available literature, the articles by van der Grond $^{6}$ and Bugnicourt ${ }^{10}$ report data similar to our own with higher percentages of complete Circles in both patients and controls. This percentage is greater than the level generally accepted as average in the literature, which estimates normal Circles as occurring in $50 \%$ of the general population, $4,7,8,11$ probably because these percentages were calculated in controls groups never selected for presence or absence of headache, a disorder with a very high prevalence in the general population. The difference in age between migraineurs and controls in our study should not impact on the prevalence of Circle variants in the two groups, as both can be considered as falling within adult middle age. Age is, in any case, of relative interest here, given that intracranial arteries begin to develop between the 20th and 30th week of intra-uterine life, ${ }^{12}$ are completed by the time of birth and remain unaltered thereafter.

Table 3: Association between types of MRI lesions and types of migraine

\begin{tabular}{|c|c|c|c|}
\hline & $\begin{array}{l}M \text { MiOA } \\
(n-204)\end{array}$ & $\begin{array}{l}M W A \\
(n 66)\end{array}$ & $\begin{array}{l}\text { OR }[95 \% \mathrm{CI}] \\
(\text { HWW } \mathrm{OS} \text { H1WA) }\end{array}$ \\
\hline Normatil MRI & $136(66.67 \%)$ & $50(75.76 \%)$ & \\
\hline Ahnormal & $68(33.33 \%)$ & $16(24.24 \%)$ & 0.6 [II.3 to 1.2 | \\
\hline (iliosis & $27(1.3 .24 \%)$ & $9(13.67 \%)$ & $0.9 \mid 0.4902 .1$ \\
\hline lacullat desjuns & $41(20.10 \%)$ & $7(10.61 \%)$ & $0.5[0.20101 .1]$ \\
\hline Supratentrorids & $36(17.6501 / 0)$ & $(10.04 \%)$ & $0.5 / 0.2 \mathrm{fo} \mathrm{S} . \mathrm{H} /$ \\
\hline Inffts- tomstrist & $1 / 0.400^{\circ}$ & - & t) $9[t] .04$ to 22.5$]$ \\
\hline 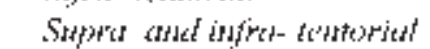 & $4 t .95 \%$ & {$[(d .57 \%)$} & $0,7 f 0.1$ fos 6.2$]$ \\
\hline
\end{tabular}

MWOA: Without Aura, MWA: With Aura; OR: Odds Ratio; [95\%CI]: 95\% Confidence Interval. 


\section{Brain lesions}

No significant relationship between circle of Willis morphology and brain lesions emerged from our study with, in particular, no link between a specific Circle morphology and the presence of infra-tentorial lacunar lesions. The influence of comorbid conditions in the migraine group was evaluated after data analysis had been performed. The presence and type of brain lesion has been analyzed in our migraine population, as a whole and also in relation to Circle anomalies. In our population $33 \%$ of MWOA and 24\% of MWA sufferers presented some kind of brain lesion. These were mainly lacunar lesions in MWOA patients, with both lacunar and gliotic lesions present in MWA subjects (Table 3). The most common site for brain lesions was the sub-cortical supra-tentorial region, with only about $2 \%$ of MRI scans demonstrating infra-tentorial lacunar lesions. Kruit's study reported an $8 \%$ level of minor vascular lesions and deep brain gliosis with no significant differences between migraineurs (both MWOA and MWA) and controls, plus an incidence of around 5\% lacunar cerebellar lesions ${ }^{5,13}$ and $4 \%$ of brainstem lesions in the headache group ${ }^{14}$. Our study populations presented higher levels of minor brain lesions, compared to Kruit's, perhaps explained by the fact that we based our study in a hospital out -patient department while Kruit used samples taken from the general population. The percentage of lacunar cerebellar lesions in the headache population was similar, however, perhaps explained by more posterior circle anomalies in migraineurs. Multivariate analysis of co-morbid conditions, migraine type and circle of Willis variants, did not evidence any significant relationship with brain lesions, the only exception being a significant prevalence of cardiovascular diseases in the MWA group when compared to MWOA. That the combined effects of basilar artery hypoplasia together with certain types of cardiovascular disease might produce aura in MWA patients via a mechanism provoking alterations in cerebral blood flow and therefore cortical spreading depression, seems an interesting hypothesis requiring further investigation. In fact, cortical spreading depression may also be triggered by cerebral ischemia, ${ }^{15,16}$ in patients known to suffer from alterations in cerebral blood flow. ${ }^{17}$ Very recently Wentland documented a significant lower blood flow in posterior cerebral areas in the same side of unilateral fetal configuration of circle of Willis, mimicking cerebrovascular disease. ${ }^{18}$ This report, together with our results of a significative link between unilateral fetal variant plus basilar hypoplasia and MWA, seems to uphold the hypothesis that aura could have a vascular ethiopathogenesis. Cucchiara recently suggested that all possible causal mechanisms, including vascular and endothelial disorders plus the presence of circle of Willis variants, should be considered when studying migraineurs, in order to "classify migraine patients according to specific factors contributing to their disease, which might have implications in selection of therapeutic strategies". ${ }^{19}$ Mull et al concluded that an incomplete circle of Willis should be regarded as a risk factor in hemispheric low-flow infarcts, ${ }^{20}$ although this idea seems to be in direct contrast with other work reporting on the protective action of fetal circle variants on deep brain lesions. ${ }^{6}$ How the frequent association of Circle variant morphologies and migraine relates to the pain of migraine or the presence of ischemic brain lesions has yet to be answered. Migraine runs in families ${ }^{21,22}$ and there may well be a genetic link between it and the inheritance of circle of Willis anomalies. ${ }^{23}$ The pain of migraine may, in turn, find an explanation among the numerous current theories on the pathogenesis of the disorder, many of which are also linked to an increased risk of stroke ${ }^{17}$ although, of course, this may prove to be an epiphenomenon and not causal at all.

\section{CONCLUSIONS}

Migraineurs present more variants in the circle of Willis than non-headache controls. These variant morphologies occur with similar frequency in both MWOA and MWA, except for posterior unilateral anomalies with and without basilar hypoplasia, which are more frequently found in MWA. The presence of circle of Willis variants does not appear to either increase nor decrease the formation of ischemic brain lesions, however. In MWA sufferers, the neuro-vascular phenomenon of cortical spreading depression could be stimulated by alterations in cerebral blood flow which, in turn, might be related to a prevalence of posterior circle variants together with basilar artery hypoplasia in these patients. Very probably, variants of the circle of Willis constitute part of the anatomy of the migraineurs phenotype.

\section{CONTRibutors}

C. Cavestro designed and conducted the study, wrote the protocol and the final report. L. Richetta and Sergio Duca performed MRI and Angio-MRI. M.R. L'Episcopo and E. Pedemonte contributed during patient selection and the preparation of data for analysis. C. Di Pietrantonj was responsible for data analysis and statistical testing. All authors contributed to the preparation of the final report.

\section{ACKNOWLEDGEMENT}

The authors thank Dr. Maria Cristina Frigeri, Director of our hospital, for her technical support and approval of our project, Dr. Josephine Taylor for the English translation, and all volunteers and patients who continue to support our research. 


\section{REFERENCES}

1. Headache Classification Subcommittee of The International Headache Society. The International Classification of Headache Disorders. 2nd ed. Cephalalgia. 2004; 24: 1-160.

2. Lovrencić-Huzjan A, Demarin V, Rundek T, Vukovic V. Role of vertebral artery hypoplasia in migraine. Cephalalgia. 1998; 18 : 684-6.

3. Paemeleire K, Proot P, De Keyzer K, Achten E, Crevits L. Magnetic resonance angiography of the circle of Willis in migraine patients. Clin Neurol Neurosurg. 2005; 107: 301-5.

4. Ikeda K, Kashihara H, Hosozawa K-i, et al. Does a fetal circle of Willis protect against white matter abnormalities in migraineurs? Headache Care. 2006; 3: 15-20.

5. Kruit MC, van Buchem MA, Hofman PA, et al. Migraine as a risk factor for subclinical brain lesions. JAMA. 2004; 291: 427-34.

6. van der Grond J, van Raamt AF, van der Graaf Y, Mali WPTM, Bisschops RHC. A fetal circle of Willis is associated with a decreased deep white matter lesion load. Neurology. 2004; 63; 1452-6.

7. Hartkamp MJ, van der Grond J, van Everdingen KJ, Hillen B, Mali WPTM. Circle of Willis collateral flow investigated by magnetic resonance angiography. Stroke. 1999; 30: 2671-8.

8. Krabbe-Hartkamp MU, van der Grond J, de Leeuw FE, et al. Circle of Willis: morphologic variation on three-dimensional time-offlight MR angiograms. Radiology. 1998; 207: 103-11.

9. Millikan C, Futrell N. The fallacy of the lacune hypothesis. Stroke. 1990; 21: 1251-7.

10. Bugnicourt JM, Garcia PY, Peltier J, Bonnaire B, Picard C, Godefroy $\mathrm{O}$. Incomplete posterior circle of Willis: a risk factor for migraine? Headache. 2009; 49: 879-86.

11. Macchi C, Lova RM, Miniati B, et al. The Circle of Willis in healthy older persons. J Cardiovasc Sur. 2002; 43: 887-90.

12. Van Overbeeke JJ, Hillen B, Tulleken CA. A comparative study of the cicle of Willis in fetal and adult life. The configuration of the posterior bifurcation of the posterior communicating artery. J Anat. 1991; 176: 45-54.
13. Kruit MC, Launer LJ, Ferrari MD, van Buchem MA. Infarcts in the posterior circulation territory in migraine. The population-based MRI camera study. Brain. 2005; 128: 2068-77.

14. Kruit MC, van Buchem MA, Launer LJ, Terwindt GM, Ferrari MD. Migraine is associated with an increased risk of deep white matter lesions, subclinical posterior circulation infarcts and brain iron accumulation: the population-based MRI CAMERA study. Cephalalgia. 2010; 30: 129-36.

15. Hadjikhani N, Sanchez del Rio M, Wu O, et al. Mechanisms of migraine aura revealed by functional MRI in human visual cortex. Proc Natl Acad Sci USA. 2001; 98: 4687-92.

16. Dietrich WD, Feng ZC, Leistra H, Watson BD, Rosenthal M. Photothrombotic infarction triggers multiple episodes of cortical spreading depression in distant brain regions. J Cereb Blood Flow Metab. 1994; 14: 20-8.17. Bednarczyk EM, Remler B, Weikart C, Nelson AD, Reed RC. Global cerebral blood flow, blood volume, and oxygen metabolism in patients with migraine headache. Neurology. 1998; 50: 1736-40.

18. Wentland AL, Rowley HA, Vigen KK, Field AS. Fetal origin of the posterior cerebral artery produces left-right asymmetry on perfusion imaging. Am J Neuroradiol. 2010; 31: 448-53.

19. Cucchiara B, Detre J. Migraine and circle of Willis anomalies. Med Hypotheses. 2008; 70: 860-5.

20. Mull M, Schwarz M, Thron A. Cerebral hemispheric low-flow infarcts in arterial occlusive disease: lesion patterns and angiomorphological conditions. Stroke. 1997; 28: 118-23.

21. Russel MB, Olesen J. Increased familial risk and evidence of genetic factor in migraine. BMJ. 1995; 311: 541-4.

22. Montagna P. The primary headaches: genetics, epigenetics and behavioural genetic model. J Headache Pain. 2008; 9: 57-69.

23. Van Overbeeke JJ, Hillen B, Tulleken CAF. A comparative study of the circle of Willis in fetal and adult life. The configuration of the posterior bifurcation of the posterior communicating artery. J Anat. 1991; 176: 45-54. 